\title{
Comparison of Riparian Evapotranspiration Estimates based on a Water Balance Approach and Sap Flow Measurements
}

\author{
R. D. Mac Nish¹, C. L. Unkrich², Evelyn Smythe ${ }^{1}$, D. C. Goodrich², and Thomas Maddock, \\ $\| I^{1}$
}

${ }^{1}$ University of Arizona, Department of Hydrology and Water Resources, Tucson, Arizona, USA. ${ }^{2}$ USDA-ARS Southwest Watershed Research Center, Tucson, Arizona, USA.

\begin{abstract}
Estimates of evapotranspiration (ET) from riparian vegetation along a 122 meter reach of the San Pedro River using both a water balance approach and by scaling up sap flow measurements are compared. A sensitivity analysis was performed on the components of the water balance to assess the effects of measurement errors on estimates of ET using this method. It was concluded that by reducing the error in three key components to less than $5 \%$, riparian ET could be estimated to an accuracy of $20-25 \%$ using the water balance method. The analysis also indicated that random measurement errors up to $10 \%$ in the water balance measurements would explain the difference between the water balance and sap flow ET estimates. Demonstrating agreement given reasonable error bounds provides confidence in the accuracy of both methods.
\end{abstract}




\section{KEYWORDS}

evapotranspiration, water balance, riparian, sap flow, groundwater, San Pedro River

\section{INTRODUCTION}

This paper presents a preliminary attempt to estimate evapotranspiration (ET) from riparian vegetation along a 122 meter reach of the San Pedro River in Cochise County, Arizona (Figure 1). ET was estimated over the entire study area using both a water balance approach, based on measurements of streamflow and ground water head distributions, and by scaling up sap flow measurements of individual trees. These measurements were acquired during three 32- to 48-hour "synoptic" periods of intensive data collection in March, April and June of 1997 representing different degrees of aquifer stress from transpiration. A sensitivity analysis was performed on the components of the water balance to assess the effects of measurement errors on estimates of ET using this approach. The analysis also indicated the degree of component error necessary to explain the difference between the water balance and sap flow ET estimates. This work is an important step towards developing a better understanding of stream-aquifer-vegetation interactions, improving our ability to simulate those systems and our ability to scale these relationships in time and space.

The San Pedro River valley is comprised of alluvial materials deposited by streams emerging from the surrounding mountains between the middle Pliocene and the middle Pleistocene time (Huckleberry, 1996) before the San Pedro River became established as a through-flowing drainage. The Lewis Springs Research Site (LSRS) is underlain by a relatively shallow 
floodplain aquifer deposited by the river after first carving a valley into the earlier alluvial deposits. Approximately $165 \mathrm{~m}$ wide and ranging in thickness up to about ten meters, the floodplain aquifer feathers out against the underlying regional aquifer at its margins. Water in the regional aquifer moves toward the river from the bordering mountains, discharging upward where it meets the floodplain aquifer. Like the river, water in the floodplain aquifer flows south to north down the valley, converging slightly toward the river, causing some discharge into the stream (baseflow).

\section{DATA ACQUISITION}

\subsection{Water Balance}

River flow measurements were carried out at five points distributed along the study reach. These included water level, current meter discharge measurements and sampling for dye tracer dilution analysis during the synoptic periods. Difficulties in analyzing data from the dye tracer dilution technique included temperature-induced variation in dye injection rates and diurnal fluctuations of water level through the study reach. The presence of a large pool between the third and fourth sampling points created intractable problems with the analysis and as a result only the gains between the first and third (X1 and $X 3$ in Figure 2) were estimated (Table 1). Average flow rates for the March and April synoptic periods were 212 $\mathrm{l} / \mathrm{s}$ and $127 \mathrm{l} / \mathrm{s}$ respectively. During the June study, a portable steel flume was installed near $\mathrm{X} 1$ to obtain accurate discharge measurements during this period of very low flow (25 l/s). 
Ground water data were collected on an hourly basis during the synoptic periods at 25 piezometers, and continuously recorded at 6 wells and one piezometer. The hourly measurements were made using electronic sounders accurate to within $3 \mathrm{~mm}$ and the continuous measurements were recorded with bubble gages also accurate to $3 \mathrm{~mm}$. The details of piezometer and well construction are presented by Mac Nish et al. (1998). The piezometer network consisted of three transects roughly perpendicular to the stream, each transect having four clusters of piezometers, two on each side of the stream, with one near the channel and one about 50 meters away (Figure 2). In each cluster, one piezometer was finished just below the depth to groundwater, and one or two additional piezometers were finished at 1- to 1.5-meter intervals below the shallowest piezometer, all within the floodplain aquifer. Depths ranged from 3.05 to 7.32 meters. The clusters were identified by their location relative to the stream (West or East), their location along the study reach (North,

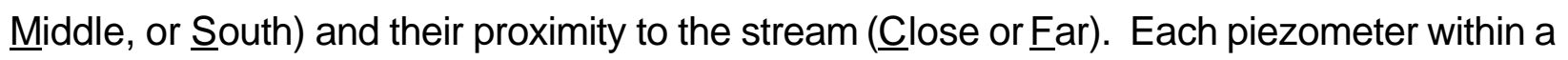
cluster was identified by its approximate depth in feet. Thus the WMC 14 piezometer was located on the west bank in the middle transect, close to the stream, and was 14 feet deep. Piezometer coordinates accurate to within several centimeters were obtained using an electronic total station, and level surveys were conducted to determine relative elevations to within 3mm.

Ground water gradients and overall groundwater level changes were computed using the average groundwater level measured in each piezometer over a 24-hour interval within each synoptic period. Horizontal gradients were computed as the average gradient between the 
middle and south clusters, using the shallowest piezometer in each cluster, paired as shown in Figure 2. In most cases the vertical gradients were computed using the two deepest piezometers in each cluster (in the case of WMC 14, a nearby, deeper observation well was used). Since these piezometers were finished near the bottom of the floodplain aquifer, the computed vertical flux should be approximately equal to the flux across its interface with the regional aquifer. The average vertical gradient during the April synoptic was substantially lower than in March or June (Table 1), probably due to recharge into the floodplain aquifer from elevated river levels caused by a storm several days earlier.

\subsection{ET From Sap Flow Measurements}

During the synoptic periods sap flow velocity was measured at selected clusters of cottonwood and willow trees in the LSRS using heat-pulse probes logging at 30 minute intervals (Shaeffer and Williams, this issue). Using core sample data, regression relationships between sap wood area (SWA) and the trunk diameter at breast height (DBH) were developed. The regression equations were combined with measurements of DBH for the 533 cottonwood and willow trees along the corridor between X1 and X3 to convert sap flow velocities $\left(\mathrm{V}_{\text {sap }}\right)$ into total volumetric $\mathrm{ET}$ rates leaving the corridor between $\mathrm{X} 1$ and $\mathrm{X} 3$ :

$$
E T=v_{\text {sap }} \cdot \sum_{x 1}^{x_{3}} \text { SWA }
$$


These rates at 30 minute intervals were then averaged over a 24 hour period, giving average rates of 0.4 liters per second (I/s) for April and $0.6 \mathrm{l} / \mathrm{s}$ for June. During the March synoptic, sap flow velocities were zero.

The error in each estimate of ET at a given 30 minute interval was assumed to be both independent and random, and was computed as:

$$
\begin{aligned}
& \varepsilon_{\mathrm{ET}}=\sqrt{\left(\frac{\partial \mathrm{ET}}{\partial \mathrm{v}_{\text {sap }}} \varepsilon_{\mathrm{v}}\right)^{2}+\left(\frac{\partial \mathrm{ET}}{\partial \mathrm{SWA}} \varepsilon_{\mathrm{T}} \varepsilon_{\mathrm{SWA}}\right)^{2}} \\
& \varepsilon_{\mathrm{ET}}=\sqrt{\left(\mathrm{SWA} \mathrm{A}_{\mathrm{T}} \cdot \varepsilon_{\mathrm{V}}\right)^{2}+\left(\mathrm{v}_{\mathrm{sap}} \cdot \varepsilon_{\mathrm{SWA}_{\mathrm{T}}}\right)^{2}}
\end{aligned}
$$

where $\varepsilon_{v}$ is the standard error of estimate from statistical analysis of the velocity data,

$$
\operatorname{SWA}_{\mathrm{T}}=\sum_{\mathrm{X} 1}^{\mathrm{X}_{3}} \mathrm{SWA}
$$

is the total sap wood area and

$$
\varepsilon_{\mathrm{SWA}_{\mathrm{T}}}=\sqrt{\sum_{\mathrm{X} 1}^{\mathrm{X} 3} \varepsilon_{\mathrm{SWA}}^{2}}
$$


is the error in the total sap wood area, where $\varepsilon_{s w_{A}}$ is the standard error from the $\mathrm{DBH}$ versus SWA regression. Adding and subtracting these errors yielded a range of average ET rates: 0.3 to $0.5 \mathrm{l} / \mathrm{s}$ for April and 0.5 to $0.7 \mathrm{l} / \mathrm{s}$ for June. Details on the measurement of streamflow and the estimation of riparian transpiration from sap flow measurements may be found in Mac Nish et al. (1998) and Williams et al. (1998) respectively.

\section{ANALYSIS}

\subsection{Water Budget for the Floodplain Aquifer}

The section of floodplain aquifer between points $X 1$ and $X 3$ was chosen as the control volume (CV) for the water balance analysis (Figure 3). Hydraulic properties within the CV are assumed to be constant and show only small-scale, random variation, which is consistent with the extremely small size of the control volume, from a groundwater perspective. Therefore, we assume that hydraulic conductivity and specific yield can be adequately represented by average values. Because the analysis is based only on flow across the boundaries of the CV, there is no need to account for gradients within the CV itself.

We define $\mathrm{R}$ to be the rate $(\mathrm{l} / \mathrm{s})$ of upward flow into the $\mathrm{CV}$ from the underlying regional. $\mathrm{U}$ and $\mathrm{D}$ are defined as the rate of flow $(\mathrm{I} / \mathrm{s})$ through the upstream and downstream cross sections of the CV. Within the CV, some water escapes to the stream as a gain $\mathrm{G}(\mathrm{I} / \mathrm{s})$ in flow between $\mathrm{X} 1$ and $\mathrm{X} 3$, leaving the $\mathrm{CV}$ as streamflow. Estimates for gain were obtained from the dye 
dilution analysis and streamflow measurements. Through all three synoptic periods groundwater levels declined, as the CV contributed to streamflow and ET at the expense of water in storage, S. In April and June an additional component leaves as ET from the phreatophytic cottonwood and willow trees. Figure 4 shows groundwater level changes at the EMF cluster during the three synoptic periods. While the March data shows a slight but steady decline, the traces for April and June show the diurnal signal caused by transpiration of the phreatophytes.

The water balance equation for each synoptic period can be written as:

$$
\varepsilon_{r}=U+R+S-D-G-E T
$$

where $\varepsilon_{\mathrm{r}}$ is the residual error of closure. Thus ET can be computed as:

$$
E T=U+R+S-D-G
$$

if the quantities on the rhs are known. In the following analysis, the hydraulic conductivity, which appears in $U, R$ and $D$, is also considered to be an unknown. We take advantage of the fact that ET was zero during March, which removes ET as an unknown for that synoptic period and allows computation of the hydraulic conductivity, which is then used in equation 7 for April and June. 
The horizontal ground water flow components $U$ and $D$ can be expressed as:

$$
\begin{aligned}
& \mathrm{U}=\operatorname{grad}_{\mathrm{H}} \cdot \operatorname{area}_{\mathrm{X}} \mathrm{U} \cdot \mathrm{K}_{\mathrm{S}} \cdot \mathrm{r}_{\mathrm{H}: \mathrm{V}} \\
& \mathrm{D}=\operatorname{grad}_{\mathrm{H}} \cdot \operatorname{area}_{\mathrm{X}} \mathrm{D} \cdot \mathrm{K}_{\mathrm{S}} \cdot \mathrm{r}_{\mathrm{H}: \mathrm{V}}
\end{aligned}
$$

where $\operatorname{grad}_{H}$ is the horizontal ground water gradient, and $\operatorname{area} \mathrm{U}$, $\operatorname{area}_{x} \mathrm{D}$ are the saturated cross sectional areas of the aquifer at $X 1$ and $X 3$. Due to alternating layers of coarse and fine sediments, alluvial aquifers as a rule show pronounced anisotropy, where horizontal conductivity is much greater than vertical conductivity. Here, $\mathrm{K}_{\mathrm{S}}$ is the vertical saturated hydraulic conductivity, assumed to be the same at both cross sections, and $r_{\mathrm{H}: \mathrm{V}}$ is the ratio of horizontal to vertical hydraulic conductivity (assumed to be approximately 10, after Freeze and Cherry, 1979). The cross sectional areas were approximated by the average saturated aquifer width multiplied by the average saturated thickness at $\mathrm{X} 1$ and $\mathrm{X} 3$ for each synoptic period (Table 1). Saturated width and thicknesses were estimated using information on aquifer thickness obtained from the piezometer boreholes and from average groundwater levels measured during the synoptic periods.

Vertical inflow from the regional aquifer can be expressed as:

$$
\mathrm{R}=\operatorname{grad}_{\mathrm{V}} \cdot \operatorname{area}_{\mathrm{P}} \cdot \mathrm{K}_{\mathrm{S}}
$$


where grad $_{v}$ is the vertical ground water gradient near the bottom of the floodplain aquifer and areap is the saturated plan area of the aquifer. The saturated area was approximated by the measured distance between $\mathrm{X} 1$ and $\mathrm{X} 3$ multiplied by the average saturated width.

The change in storage was computed as:

$$
\mathrm{S}=\frac{\Delta \mathrm{h} \cdot \operatorname{area}_{\mathrm{P}} \cdot \mathrm{S}}{\Delta \mathrm{t}}
$$

where $\Delta \mathrm{h}$ is the average groundwater level change over a 24 hour interval $(\Delta t=86400 \mathrm{~s})$ during each synoptic period (Table 1) and $s$ is the specific yield, estimated to be approximately 0.2 (Freeze and Cherry, 1979).

Two variables which remain unknown are $\mathrm{K}_{\mathrm{S}}$ and $\mathrm{ET}$. Since $\mathrm{ET}$ was zero during the March synoptic, $\mathrm{K}_{\mathrm{S}}$ can be computed directly from the water balance equation for March:

$$
\mathrm{K}_{\mathrm{s}}=\frac{\mathrm{G}_{\text {March }}-\left[\Delta \mathrm{h} \cdot \operatorname{area}_{\mathrm{P}}\right]_{\text {March }} \cdot \frac{\mathrm{s}}{\Delta \mathrm{t}}}{\operatorname{grad}_{H} \cdot \mathrm{r}_{\mathrm{H}: \mathrm{V}}\left[\operatorname{area}_{\mathrm{x}} \mathrm{U}-\operatorname{area}_{\mathrm{x}} \mathrm{D}\right]_{\text {March }}+\left[\operatorname{grad}_{\mathrm{V}} \cdot \operatorname{area}_{\mathrm{P}}\right]_{\text {March }}}
$$

The value of $K_{s}$ (vertical conductivity) computed from equation 12 is $0.025 \mathrm{~mm} / \mathrm{s}$. The corresponding horizontal conductivity value of $0.25 \mathrm{~mm} / \mathrm{s}$ is somewhat high for silty sand aquifers (Freeze and Cherry, 1979), but given the presence of sand and gravel stringers, particularly near the stream, it is a defensible value in this case. 
Assuming conductivity is constant between synoptic periods, the $\mathrm{K}_{\mathrm{S}}$ value can then be used with the average gradients and cross sectional areas for the April and June synoptic periods to compute values of average ET during those periods, where:

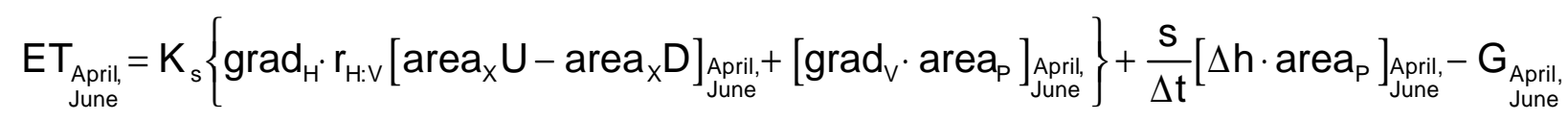

The resulting ET rates for April and June are $0.6 \mathrm{l} / \mathrm{s}$ and $1.3 \mathrm{l} / \mathrm{s}$, respectively. Neither ET values were within the assumed error range of the sap flow estimates $(0.3$ to $0.5 \mathrm{l} / \mathrm{s}$ for April and 0.5 to $0.7 \mathrm{l} / \mathrm{s}$ for June). This discrepancy motivated a sensitivity analysis which became the basis for an independent assessment of error in the sap flow ET estimates and for estimating errors in the ground and surface water components of the water balance.

\subsection{Error and Sensitivity Analysis}

The maximum error in computing average horizontal gradients was estimated to be less than $2 \%$ based on the horizontal and vertical precision of the piezometer surveys and the average error of groundwater level measurements during the synoptic studies. Consideration of the previously discussed problems with the dye dilution measurements suggested an error of about $10 \%$ in the streamflow gain. The estimation error or uncertainty in the remaining water balance components was impossible to ascertain directly. However, if both the water balance 
and sap flow estimates are sufficiently close to the true values, then for reasonable error bounds on the water balance and sap flow measurements the resulting ranges of ET estimates should overlap. Therefore, to quantify the error in the water balance components, the error bounds on the water balance measurements were expanded until the resulting range of ET values overlapped those from the sap flow measurements. To obtain a more conservative estimate of the error it was further required that the range of ET values from the water balance include the sap flow estimates themselves rather than just overlap the sap flow error range.

This was implemented in an iterative computer algorithm, using the error estimates for horizontal gradients and streamflow gain, assuming errors at first up to $5 \%$, and then up to $10 \%$, in the remaining variables and then adjusting them within these error ranges until the resulting ET values exactly matched the values estimated from the sap flow measurements. Vertical conductivity $\mathrm{K}_{\mathrm{s}}$ was also constrained to values less than or equal to $0.02 \mathrm{~mm} / \mathrm{s}$ as a conservative upper bound for the type of aquifer material. Since the errors were assumed to be random rather than systematic, most variables were adjusted independently not only within a given synoptic period but also between synoptic periods, i.e., the gain in March was varied independently from the gain in April. Variables were adjusted by applying a separate multiplier $\rho$ to each variable, where each multiplier varies independently in three discrete steps. As an example, for $\pm 10 \%$, $\rho$ would vary among the three values $\{0.9,1.0,1.1\}$.

A general sensitivity analysis based on a $10 \%$ error range was then carried out by holding a 
given variable constant while allowing the others to vary independently as described above. Sensitivity was assessed using the root mean squared error (RMSE) of the computed ET values relative to the original values for both April and June, summed over all (- 150 billion) possible multiplier combinations. To help quantify the benefit of striving for more accurate measurements, the drop in RMSE was examined while the error range of individual variables was reduced from $10 \%$ to $5 \%$, starting with the most sensitive and proceeding to the least sensitive variable. The procedure was then repeated, this time reducing the range from $10 \%$ to $2 \%$.

The adjusted horizontal to vertical conductivity ratio $r_{\mathrm{H}: \mathrm{v}}^{\prime}$ and specific $\mathrm{s}^{\prime}$ yield do not vary between synoptic periods:

$$
\begin{aligned}
& r_{H: V}^{\prime}=r_{H: V} \cdot \rho_{1} \\
& s^{\prime}=s \cdot \rho_{2}
\end{aligned}
$$

The adjusted $\mathrm{K}_{\mathrm{S}}$ was computed using the March $(\mathrm{ET}=0)$ water balance:

$$
K_{s}^{\prime}=\frac{\rho_{3} \cdot G_{M a r c h}-\rho_{4} \cdot \Delta h_{M a r c h} \cdot \rho_{5} \cdot \operatorname{area}_{P_{\text {March }}} \cdot \frac{s^{\prime}}{\Delta t}}{\rho_{6} \cdot \operatorname{grad}_{H} \cdot r_{H: V}^{\prime}\left[\rho_{7} \cdot \operatorname{area}_{x} U-\rho_{8} \cdot \operatorname{area}_{x} D\right]_{\text {March }}+\rho_{9} \cdot \operatorname{grad}_{V} \cdot \rho_{5} \cdot \operatorname{area}_{P}}
$$


Using the adjusted $\mathrm{K}_{\mathrm{S}}$ computed from March, the adjusted ET values for April and June were computed as:

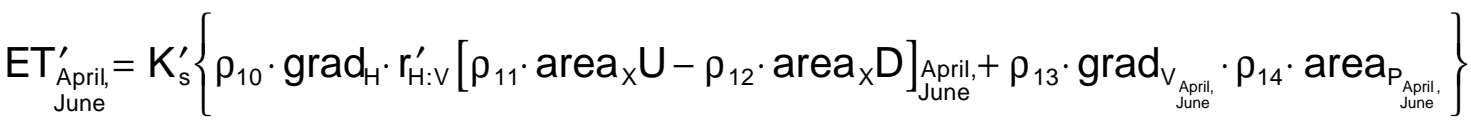

$$
\begin{aligned}
& +\frac{\mathrm{s}^{\prime}}{\Delta \mathrm{t}} \cdot \rho_{15} \cdot \Delta \mathrm{h}_{\substack{\text { April, } \\
\text { June }}} \cdot \rho_{14} \cdot \operatorname{area}_{\substack{\mathrm{P}_{\text {Aprin }}, \mathfrak{c} \\
\text { unne }}}-\rho_{16} \cdot \mathrm{G}_{\substack{\text { April, } \\
\text { June }}}
\end{aligned}
$$

Adjustments up to $5 \%$ did not allow convergence to the sap flow-derived ET values, but adjusting up to $10 \%$ did, suggesting that errors were probably greater than $5 \%$ and likely in the neighborhood of $10 \%$, which is quite remarkable given the rough estimation of some of the variables in question. This demonstrates basic agreement between the water balance and sap flow ET estimates, given a reasonable magnitude of error in the water balance, and reinforces the validity of the ET estimates from each approach.

The degree of sensitivity is indicated by the decrease in variability (RMSE) when a given variable is held constant. The sensitivity of ET estimates to deviations up to $10 \%$ is shown in Figure 5 . The results of successively dropping the deviations from $10 \%$ to $5 \%$ and from $10 \%$ to $2 \%$ are shown in Figure 6 . As we believe the error in horizontal gradients is already less than $2 \%$, Figure 6 suggests that reducing the error in aquifer area, vertical gradient and streamflow gain from $10 \%$ to $5 \%$ would reduce the uncertainty in ET estimates from about 0.9 $\mathrm{l} / \mathrm{s}$ to $0.1 \mathrm{l} / \mathrm{s}$. 


\section{CONCLUSIONS}

To indirectly assess the degree of error in the surface and ground water measurements, their values were adjusted independently until the resulting range of ET values computed from the water balance included those from the sap flow estimates. The degree of variation required was $10 \%$, which is equivalent to agreement between the two methods given random errors up to $10 \%$ in the water balance measurements. Demonstrating agreement by assuming a believable range of error provides confidence in the accuracy of both ET estimates. The sensitivity of the water balance to error in its various components was also explored, and it was concluded that by reducing the error in aquifer area, streamflow gain and vertical ground water gradient to less than 5\%, riparian ET within the LSRS could be estimated to an accuracy of about $0.1 \mathrm{l} / \mathrm{s}$ or $20-25 \%$ using the water balance approach.

A detailed survey of the aquifer boundaries using accurate equipment such as an electronic total station or differential GPS would improve our estimation of the aquifer extent. Because of the small area involved, positional accuracy is important, as well as a sufficient density of survey points to capture any major irregularities when outlining the boundaries. A more detailed description of the transverse aquifer profiles at $X 1$ and $X 3$ would allow more accurate estimation of the cross-sectional saturated area available for throughflow. At the LSRS, the regional aquifer is substantially higher in clay content than the floodplain aquifer, lending hope 
that measurements could be done with shallow seismic profiling or electrical resistivity equipment. Such data might also shed some light on the uniformity of material composing the floodplain aquifer, and thus on the uniformity of hydraulic conductivity.

The sensitivity analysis performed on the water balance components indicates that for estimating horizontal ground water gradients, the existing piezometer network and measurement techniques are probably sufficient. However, decreasing the uncertainty in vertical gradient calls for more precise measurement of groundwater levels since the difference in groundwater level occurs over the relatively small differences in well depth. Ideally, high-accuracy depth sensors should replace the manual measurement methods used for this study. Additionally, the deeper piezometers in each cluster should be rehabilitated or reconstructed to better isolate the openings from overlying saturated materials.

Unfortunately, dye injection techniques were apparently not suitable for obtaining accurate estimates of streamflow gain due to temporary dye storage problems in pools and hyporheic flow zones (Bencala and Walters, 1983). Flumes or weirs equipped with recording devices are required for more accurate measurement of streamflow at the upstream and downstream boundaries. 


\section{ACKNOWLEDGEMENTS}

Financial support from the USDA-ARS Global Change Research Program, the USDA National Research Initiative Grant Program, the Arizona Department of Water Resources, and

the U.S. Bureau of Land Management is gratefully acknowledged. Assistance was also provided in part by the EPA STAR Graduate Student Fellowship Program, the National Science Foundation, the U.S. Geological Survey, the Cochise County Highway and Flood Control Department, and Ft. Huachuca. The authors wish to express their deep appreciation to the many SALSA collaborators who provided data, support, and advice in both the data acquisition phase, and in the development of this paper. We particularly appreciate the efforts of the many volunteers who participated in the data collection aspects of this study.

\section{REFERENCES}

Bencala, K. E. and R. A. Walters, 1983. Simulation of Solute Transport in a Mountain Pool N - Riffle Stream: A transient Storage Model. Water Resources Research, 19:3: 718 724, June 1983.

Freeze, R. A., and J. A. Cherry, 1979. Groundwater. Prentice-Hall, NJ, 604p.

Huckleberry, G., 1996. Historical Channel Changes on the San Pedro River, Southeastern Arizona. Arizona Geological Survey Open-File Report 96 -15, 21p. 
Mac Nish, R. D., Peters, C. J., Schulte, M. A., Goodrich, D. C., Pool, D. R., Maddock III, T., Unkrich, C. L., Whitaker, M. P. L., and B. F. Goff, 1998. Quantification of Groundwater-Surface water Interactions in a Southwestern Riparian System. American Meteorological Society, Special Symposium on Hydrology, Phoenix, Arizona, 11-16 Jan 1998, Session 1: Integrated Observations of Semi-Arid Land-Surface-Atmosphere Interactions, Paper-P2.12.

Schaeffer, S. M. and D. G. Williams, 2000. Transpiration in Cottonwood/Willow Forest Patches Estimated from Sap Flux. Journal of Agricultural and Forest Meteorology, (this issue).

Williams, D. G., Brunel, J-P., Schaeffer, S. M. and K. A. Snyder, 1998. Biotic Controls Over the Functioning of Desert Riparian Ecosystems. American Meteorological Society, Special Symposium on Hydrology, Phoenix, Arizona, 11-16 Jan 1998, Session 1: Integrated Observations of Semi-Arid Land-Surface-Atmosphere Interactions, Paper-P1.11.

FIGURE CAPTIONS

Figure 1 Location of the Lewis Springs Research Site (LSRS) in the Upper San Pedro River Basin in Cochise County, Arizona. 
Figure 2 Map showing the locations of piezometers used to compute horizontal and vertical gradients. Piezometer clusters are identified by their location relative to the stream (West or East), their location along the study reach (North, Middle, or South) and their proximity to the stream (Close or Far). Each piezometer within a cluster is identified by its approximate depth in feet. Piezometers used to compute horizontal gradients are connected by lines, and those used to compute the vertical gradient at a given cluster are indicated by an asterisk. Locations where river flow measurements were taken are indicated by $\mathrm{X} 1$ and $\mathrm{X} 2$.

Figure 3 Simplified schematic of the water budget for the floodplain aquifer system.

$\mathrm{ET}=$ evapotranspiration of cottonwood and willow trees

$R=$ inflow from the regional aquifer

$U=$ upstream inflow within the floodplain aquifer across $X 1$

$D=$ downstream outflow within the floodplain aquifer across $X 3$

$\mathrm{G}=$ streamflow gain between $\mathrm{X} 1$ and $\mathrm{X} 3$

$S=$ water released from storage as water levels drop within the floodplain aquifer

Figure 4 Water level elevation changes during and between March, April, and June synoptic studies in the 10 and 15 foot deep piezometers of the East Middle Far cluster at the LSRS.

Figure 5 Sensitivity of water balance estimates of ET to measurement uncertainty in 
individual components as indicated by the drop in RMSE when a given variable is held constant

Figure 6 Effect of successively reducing measurement uncertainty in individual water balance components, from $10 \%$ to $5 \%$ and from $10 \%$ to $2 \%$, on uncertainty in ET estimates (None $=$ all variables at $10 \%)$. For area $a_{p}$ and $G$, the difference between $5 \%$ and $2 \%$ is indistinguishable. 


\begin{tabular}{lrrr}
\hline Component & March & \multicolumn{1}{c}{ April } & \multicolumn{1}{c}{ June } \\
\hline Horizontal gradient & .0021 & .0021 & .0019 \\
Vertical gradient & .0076 & .0019 & .0071 \\
Average groundwater level change $(\mathrm{m})$ & .007 & .009 & .007 \\
Gain $(\mathrm{I} / \mathrm{s})$ & 4.5 & 0.8 & 2.4 \\
ET from sap flow $(\mathrm{l} / \mathrm{s})$ & 0.0 & 0.4 & 0.6 \\
Saturated thickness at X1 $(\mathrm{m})$ & 4.3 & 4.2 & 4.0 \\
Saturated thickness at X3 $(\mathrm{m})$ & 3.7 & 3.6 & 3.5 \\
Average saturated width $(\mathrm{m})$ & 175 & 165 & 155 \\
Aquifer length (X1 - X3) $(\mathrm{m})$ & 122 & 122 & 122 \\
Saturated cross-sectional area at X1 $\left(\mathrm{m}^{2}\right)$ & 743 & 686 & 620 \\
Saturated cross-sectional area at X3 $\left(\mathrm{m}^{2}\right)$ & 652 & 601 & 543 \\
Saturated plan area of aquifer $\left(\mathrm{m}^{2}\right)$ & 21336 & 20117 & 18898 \\
\hline
\end{tabular}

Table 1. Estimated values for ground water, surface water and sap flow components used in the water balance equations applied between $\mathrm{X} 1$ and $\mathrm{X} 3$ during the synoptic periods. 


\section{INTERPRETIVE SUMMARY}

Water use by riparian vegetation along a 122 meter reach of the San Pedro River was estimated by two methods: (1) a water balance approach, using measurements of surface and ground water flow, and (2) extrapolating measurements of sap flow for a subset of trees to the entire reach. An analysis was performed to assess the effects of measurement errors on water balance estimates of water use. It was concluded that by reducing the error in three key components to less than $5 \%$, riparian water use could be estimated to an accuracy of 20 $25 \%$. The analysis also indicated that random errors up to $10 \%$ in the water balance measurements would explain the difference between estimates from the two methods. Demonstrating agreement given reasonable error bounds provides confidence in the accuracy of both methods. 